\title{
Organization of Project Work with the Help of Digital Technologies in Teaching Russian as a Foreign Language at the Initial Stage
}

\author{
https://doi.org/10.3991/ijet.v16i22.20573 \\ Elena P. Panova ${ }^{1(\bowtie)}$, Elena V. Tjumentseva ${ }^{2}$, Ilona A. Koroleva ${ }^{3}$, \\ Elmira R. Ibragimova ${ }^{4}$, Vadim O. Samusenkov ${ }^{5}$ \\ ${ }^{1}$ Moscow Polytechnic University, Moscow, Russian Federation \\ ${ }^{2}$ Volgograd state technical university, Volgograd, Russian Federation \\ ${ }^{3}$ Volgograd State Social and Pedagogical University, Volgograd, Russian Federation \\ ${ }^{4}$ Kazan Federal University, Elabuga, Russian Federation \\ ${ }^{5}$ Sechenov First Moscow State Medical University, Moscow, Russian Federation \\ e.p.panova@mospolytech.ru
}

\begin{abstract}
The basis of the article is the research which is devoted to the organization of project work in teaching Russian as a foreign language. The principles of project work, its role in the educational process and the implementation of project work in both full-time and distance learning are considered. The analysis of these two types of project work is carried out, the advantages and disadvantages of the distant format in the implementation of the project method are revealed.
\end{abstract}

Keywords-project work, project method, socio-cultural adaptation, intercultural communication, communication skills, distance learning, digital technologies

\section{Introduction}

Project work is one of the most successful methods that is being successfully implemented in Russian universities now. The project method has proven itself quite well since it is in the process of learning through project work that students develop the ability to work independently, develop critical and creative thinking; they also learn to work in groups, they develop practical and communication skills (reading, writing, speaking). "Project work helps the teacher solve a very important task: to include each student in the active cognitive activity. The project method helps students learn to set goals and find ways and means to achieve them. It is necessary to point out that project work is a level of organization of students' activities that focuses on creating a product, a material object. However, project work is based on the formulation and solution of the problem, therefore, the method is based on independent learning as the student does not receive any ready-made knowledge from a teacher, the project is constructed jointly in the process to develop an understanding between the student and the teacher: "In 
order for such construction to be possible, students must make independent efforts to search, process, analyze data, plan their actions to communicate with various interested parties. Since such work usually goes beyond individual actions, it requires group (team) work. Further on we will mainly talk about the project-oriented approach bearing in mind that it necessarily includes problematization" [20].

\subsection{Problem Statement}

Currently, much attention is paid to the use of the project method in teaching students. We were interested to see how this training method of project work is implemented in terms of full-time and distance learning, to find out the advantages and disadvantages that arise in the distance learning format, to compare full-time and distance learning formats and their impact on the development of communicative skills and socio-cultural adaptation of students.

\subsection{Research Questions}

1. What is a project-based learning method?

2. How does project work function in the context of full-time and distance learning?

\subsection{Purpose of the Study}

The purpose of the research which is the basis of the article is to analyze and compare the implementation of project work as an educational method in full-time and distance learning.

\section{$2 \quad$ Materials and methods}

The methodological basis of the study is made up of the principles and provisions of the systemic, structural-functional and comparative-typological approaches. An important methodological guideline in this study is the works of such Russian developers of distance learning as Samoilenco V., Tretyakova T.V., Kalimullina O.V. who write about the modification of modern higher education through distance learning $[30 ; 40$; 18]. Ideas about the modernization of higher education are developed in works by Kuzu Ö.H. [23]. An in-depth analysis of the transformation of higher education using digital technologies is found in the works of Seres L. [35], Baidenko and Selezneva [5], Samoilenko [30]. Dexeus C. writes about the revolutionary process in the higher education system which is happening today with an unprecedented speed [12]. Sandkuhl $\mathrm{K}$. spoke about the consequences of the transformation of the traditional education system [31]. Akhmetova's observations on the use of digital technologies in the sphere of inclusive education are of great interest [1]. Making various fields of activity in higher education digital is also being actively discussed in modern pedagogy $[19 ; 24 ; 25 ; 28$; $34 ; 36]$. Global innovation networks and their influence on education were analyzed by Dudukalov et al. [13]. 
Scientists from different countries believe that modern students are a new generation or "network generation", which focuses on new forms of education. Digitalization of the educational process of higher education is a natural phenomenon for modern students, they give preference to it, as they consider it more natural, adequate and goaloriented $[11 ; 38 ; 39 ; 33 ; 8 ; 23 ; 6]$.

M. Brown claims that digital teaching methods have been added to traditional faceto-face education, which has led to the fact that the methods are now mixed / hybrid [9].

Almaraz-Menendez, F., Maz-Machado, A., \& Lopez-Esteban, C. correctly note that distance education has become more flexible, accessible [3], thus, all scientists come to the conclusion that modern education needs to be reshaped and adapted to meet the needs and requirements of a new "network" generation.

\section{Results and discussion}

It is known that project work is characterized by the following factors: 1) activitybased learning (learning by doing); 2) the role of the tutor. The approach is centered on the student (Student-centered learning); 3) interdisciplinarity; 4) collaboration and group work; 5) final product [21, p. 3-5]. Thus, in the course of project activity students work on creating a material object in reality, there is no any artificially simulated situation. The teacher helps students to construct a project independently, stimulating the development of various types of thinking, and above all, reflection [32]. We also have to add that the problems that are in the center of project work are at the intersection of various disciplines. It is interdisciplinarity as one of the phenomena of project work that helps to form the necessary skills for this type of activity in a student [16]. "Project work requires close interaction both within the group and with external parties, which develops communication, planning and teamwork skills. Types of project work can range from standard academic work to a music show or board game" [20].

In the process of project work such activities which are focused on the creation of artifacts or products can be considered; the result of this work can be a report or a presentation or an essay or a creative performance [10]. As part of the experience of organizing project work in Russian as a foreign language there are many types and ways to implement it [7]: Olympiads, festivals, linguistic tourism, essays, scientific reports with presentations; creative contests of postcards, posters; reading contests, theater performances, conferences, course projects, different clubs, creation of dictionaries, readers' diaries, etc.

For example, as part of project work, the Moscow Polytechnic University hosts a festival called "We are for peace". This is a large-scale event that involves foreign students from the near abroad and foreign countries. These students are studying at the preparational courses, bachelor's, master's and postgraduate courses. The festival includes several stages, each stage is held on a competitive basis:

- essay contest: a scientific and educational project, in the process of working on which "students learn to express in writing and correctly formulate their own thoughts, prove their point of view, analyze information, give examples as evidence, 
argue, demonstrate creative thinking and writing skills" [14, p. 22] the contest named "My favorite national dish" is a creative competition that helps students get acquainted with the peculiarities of the culture of other countries (with the peculiarities of national cuisine); it also helps to activate creativity, develop speaking skills (students present their dish in Russian). Students learn to keep up with the public, make monologues, in addition, at the preparatory faculty they already learn the basics of oratory in Russian.

- postcard contest: an informational and educational presentation contest where students participate in the development of an oral text about their country (its cultural and economic features) and in the preparation of the presentation. In the process of preparing of this project, students learn to work with new material in a non-native language, learn to analyze it, systematize it and learn communication skills in speaking, writing, reading, and listening.

- creative competition: (performance of a song or national dance). The goal of this project is to introduce students to the culture of other countries that is to develop cross-cultural communication skills. This is a creative project, the main activity of which is role-playing based on the method of co-creation.

- project: students demonstrate their skills by presenting the culture of their country with the help of the project, which enables them to pass through various stages of social adaptation. On the basis of the University several events are held that allow students to be gradually engaged in activities that form students' socio-cultural adaptation. These include the festival "We are for peace", which allows students to help overcome the adaptation difficulties that arise in the sphere of relations with different ethnic groups (see the third stage)" [29, p. 84]. Thus, this event implements all the main tasks that this type of work such as project sets for itself.

Due to the difficult situation in the country connected with the COVID-19 pandemic, the whole process of education was forced to be transferred to a distant format. Under quarantine an attempt was made to conduct project work dealing with foreign students in a distant format. There was a strong necessity to give up traditional training for a certain period of time and work in a digital format. Humanity has gained invaluable experience in organizing the education system in the digital mode of lectures, practical classes, including classes related to project work.

It is known that despite the fact that distance learning has its advantages, such as "independence, openness, flexibility, adaptability, mass character, efficiency, use of information technologies" [41], in distance learning there is also a whole set of significant disadvantages: "here is the list of the disadvantages of distance learning: 1. Low degree of implementation of an individual approach. 2. Lack of opportunity to communicate with both the teacher and groupmates in the process of live communication. 3. Lack of development of listening and speaking skills. 4. Inability to organize a qualified control. 5. Poor technical readiness of universities, teachers and students to work in the distance learning mode. 6. The inability to implement the method of co-creation and cooperation, which makes it impossible for students to adapt to the socio-cultural environment and cross-cultural communication among students. 7 . Difficulties that arise as a result 
of "misunderstanding" of people when interacting due to distance learning. 8. Difficulties in mastering specific material by students online. 9. Psychological and health problems that arise in the learning process. 10. Limited choice of instructional techniques for teaching students with the help of digital technology. 11. Technical communication failures that interfere with the effectiveness of training. 12. Increased fatigue of both students and teachers" [27, p. 100].

Therefore, not many projects were selected for implementation (given the awareness of all the pros and cons of conducting project work in a digital mode). The choice was influenced by a number of additional factors: 1) the impossibility to conduct many projects remotely as the student and teacher are deprived of live communication and are limited by the screen factor; 2) the necessity to consider different types of people's thinking which are used in the process of both digital and traditional learning; 3) the need to overcome various barriers that arise among the teacher and students.

Let us examine how different types of thinking of participants in the process of organizing project work in a digital format affect the quality of education. For example, Kuleshov A. claims that "students are representatives of a new generation, they live in a completely different way, having digital thinking. And teachers are mostly representatives of the old generation with the so-called analog thinking, who due to specific circumstances are forced to adapt to the digital environment. Therefore, a conflict in learning arises: globalization versus localization" [22]. Indeed, the older generation hardly accepts new forms of education, hardly learns new methodological techniques and approaches that can be applied in distance learning [37; 15]. At the same time, it must be remembered that the losses in this case are significant and we can only give basic education skills, only some basics of education, no depth and comprehensiveness can be considered.

At the same time there is a need to mention the barriers that may arise when implementing digital technologies in the organization of project work at the initial stage of learning Russian as a foreign language, namely: "cognitive (when perceiving educational material through digital technologies); - content barriers (the language of the device or software does not coincide with the student's native language); - didactic (students are not ready to learn using digital technologies, and the teacher does not have facilitation skills in inclusive education); - financial (costs for the latest technologies and software)" [2, p. 144].

The organizers understood that the emergence and overcoming of barriers in the process of organizing and conducting project work in the digital mode will significantly affect the quality of the final result, the quality of the final product [26; 13]. In addition to all that has been said, experts in the field of medicine and pedagogy have repeatedly stated that " the proposed technologies have not been experimentally tested, that children will lose their writing skills and, as a result, their ability to create and perceive large texts, screen addiction will appear and social skills will decrease. Thus, this threatens digital dementia, computer addiction, and eventually - chipization and total shadowing of the child and control of the family. All these risks and threats of digitalization are proved by individual researchers of research centers" [2, p. 144]. 
That is why, when implementing project work online, it is necessary to rely on and form a number of psychological and pedagogical competencies. In pedagogy competencies are an ideal model of behavioral manifestations that allow a person to achieve results and be effective in this type of activity [4]. Thus, when introducing project work in a distant format, it is necessary to develop such basic qualities of the individual which include the application of knowledge, skills and abilities that generate the readiness of the future specialist to carry out professional activities in any (including non-standard) situation. In other words, the projects, that students should create online, must form students' ability to apply professional knowledge, skills and personal qualities for successful activity in a particular field. In General, the methodology can name the following criteria for identifying psychological and pedagogical competencies in the process of organizing project work for foreign students at the initial stage of training: cognitive (the desire to build up psychological and pedagogical knowledge, the desire for selfknowledge), motivational (the presence of motivation for successful professional activity, the presence of professionally important personal qualities), reflexive-facilitation (the ability to analyze the pedagogical situation, control yourself), information and communication (the ability to work with information, ability to build successful communication) [2].

Intercultural competence (the ability to communicate successfully with representatives of other cultures); linguistic competence (intuitive knowledge of the language that allows it to express thoughts verbally in Russian correctly).

The process of project preparation, including the distant mode, has several stages that have already been described several times in the methodology. At the first stage the student and teacher in the process of contact using Skype determine the goals and objectives of the project, analyze the problem. The second stage is the preparation of the project itself. Here students independently analyze new material, choose ways to implement their scientific, educational and creative activities by themselves. The teacher only directs and corrects students' work through online consultations and e-mail correspondence and expresses his or her disapproval or approval of the student's work. The third stage is project implementation, a report on the work done on the project. The fourth stage is to evaluate the project according to certain conditions that were developed earlier. This can be either a collective assessment or a teacher's assessment or a committee's assessment or, what is most effective, the assessment can be made by the competition jury since the level of motivation and responsibility of students for their project increases in the competition. A healthy competitive environment is emerging in which all conditions are created for the realization of the student's creative potential [17].

Foreign students were invited to participate in the creation of projects on a competitive basis such as the competition "Postcard to a veteran", "Postcard to the Day of Russia", "Postcard to a medical worker". The obligatory requirement of this competition was a greeting text in verse or prose, considering all the norms of etiquette accepted in Russian speech and in Russian culture. The card may be accompanied by a voice recording that develops the skills of speaking, the text that the student can use to create their cards (a quotation, poem or text of their own composition) develops writing skills 
in a foreign language, introduces the student to the peculiarities of the Russian etiquette, helps to learn the culture of a foreign country.

An essay contest was also held on the following topics: "How I see Russia in the XXI century", "Anti-corruption activities in the field of education in your country". By creating this project, foreign students learn to work with the Internet databases, learn to search, organize and analyze material, develop communication skills; their critical and creative thinking develops.

The photo contest "Russia through the eyes of youth" develops not only imagination and imaginative thinking, but also communication skills as the obligatory requirement for the contest was to come up with a name for the photo and write your own interesting unusual story that would comment on the image in the photo.

The participation of foreign students in these projects helped to develop communication skills but not in full as there is no feedback from the teacher, there is no possibility of co-creation (working in a team, in a group), the possibility of live communication. For example, working on an essay develops writing skills, the ability to work with information and, consequently, reading skills as well, the ability to set specific goals and tasks in accordance with the topic of the essay. Creative contests for making postcards, emblems and posters develop writing and reading skills, the ability to work with the Internet information and use imaginative thinking. Creating a video clip develops speaking skills (mainly monologue). Listening skills are partially compensated during consultations with the teacher which are organized using Skype technologies. By participating in projects, students get acquainted with the culture of another country, learn the aesthetic and ethical principles that the culture of another country is based on, strive to learn to understand this culture and learn cross-cultural communication skills. The ability to analyze the learning process is also developed.

The result of this stage of work was an experiment conducted with the participation of foreign students involved in the projects listed above. The survey of recipients had the following objectives: to identify the advantages and disadvantages of implementing project work in a distance format, its effective or ineffective impact on the development of cognitive, research and creative skills of students in a situation of learning through digital technologies.

Those, who took part in the projects described above, participated in the survey, namely foreign students of the preparatory Department of the Moscow Polytechnic University and the Volgograd State Technical University. The survey revealed the following advantages: almost $98 \%$ of students liked to participate in the event, $99 \%$ noted that participation in projects, despite the fact that they were conducted remotely, played a positive role in improving their level of knowledge of the Russian language. All the students noted that they learnt a lot of new things in the field of vocabulary, grammar, syntax and intonation of the Russian language. 99\% said that it was difficult to prepare for this event (competition, conference, project, promotion) and only $1 \%$ did not experience any difficulties in preparing the project: "It was very tiresome to prepare for this competition because I am in a new environment and studying a new subject. I had to work hard to prepare good topics so that I could succeed in this project". 
The vast majority of respondents (99\%) said that working on the project allowed them to expand their knowledge of Russian history, culture and art. The students wrote the following:

"Participating in these projects helped me learn more about Russia and Russian people. I understood the original Russian culture, fell in love with the famous Russian cuisine and managed to feel Russian poetry". "While preparing to participate in this kind of work, I got acquainted with specialized words, was able to read and study a lot of new topics that I hadn't even heard about before and learnt a lot about Russian politics".

In the item: "Write 2-3 positive characteristics of distant participation in the events", students wrote that "to participate in such events you do not need to spend time on the road, you can participate without leaving your office (home)"; "thanks to online meetings participants in different cities and countries can discuss projects at any time. It is possible to develop a strategy and tactics for project implementation with the teacher"; "it is easier to exchange documents, project results, conduct evaluation and save time on sending documents"; "The result of participation in project work by using digital technology was that I got to know the Russian language, increased my level of motivation, got more information in the field of knowledge not only of Russian culture but also grammar, syntax".

The students also said that participation in project work, despite its distant nature, helped them become more confident, believe in themselves, helped them take up their free time with interesting things and aided them to acquire important knowledge and practical skills.

The following question was answered in different ways: "Are there any differences between face-to-face and distant participation in similar events? What is the difference?" - $98 \%$ of the recipients said that, as a rule, "a traditional meeting will be prepared and announced in advance. This allows participants to prepare for participation in the project carefully"; "the environment or atmosphere that is created in a situation of live, direct participation in a competitive project sets up students to participate in it seriously"; "All the participants can directly contribute to the development of events, comment and evaluate the final result obtained through participation in the project, make decisions, create a festive atmosphere of the event itself"; "In face-to-face competitions you can exchange new thoughts and achieve much better results"; "during such participation an atmosphere of joy, excitement, competitiveness and, at the same time, peace and unity is created - which is valuable and irreplaceable, people get an invaluable experience of empathy in creativity and joint activities".

$84 \%$ of the respondents believe that participation in the full - time event was more difficult than in distance learning, since in terms of acquired skills in the field of knowledge of the Russian language, "skills in the art of speaking a non-native language are required" and from a psychological point of view - "courage and bravery".

$89 \%$ of the recipients said that if they had been personally helped to prepare for the event by a teacher, the result would have been higher.

In the course of the survey, the students identified shortcomings that automatically arise from participating in project work in a distant format: "may cause inconvenience 
to those who haven't been exposed to online meetings before"; "With the help of specialized software for online meetings enterprises will have to install hardware and software. So, for small and medium-sized enterprises it can be expensive"; "in distance competitions it is not clear whether the participant actually did it himself or someone else helped him"; "there are no more emotions and pleasant moments".

Also, the majority claims that the shortcomings in the organization of distance learning were poor communication and technical unpreparedness for distance learning of both students and universities.

The following question was answered in different ways as well: "Have you learnt to communicate with other people better through distant participation in the competition, have you become more sociable?" - 98 percent of the recipients answered that they had to either communicate only with the teacher via Skype or solve all their questions independently. In the process of creating the project, the students were deprived of mutual cooperation and mutual communication, which excludes the possibility of implementing socio-cultural adaptation and does not teach cross-cultural communication skills. $100 \%$ of the respondents wrote that they did not find new friends in the process of participating in the distant project work.

\section{Conclusion}

During the experiment the pros and cons of the distant format were identified. Here is at first a list of the positive aspects.

1. The development of critical and creative thinking

2. The ability to work independently

3. The ability to navigate online resources

4. The ability to analyze and select the necessary information

5. The development of imaginative thinking

6 . The increasing of the level of motivation

The negative points were also mentioned.

1. The impossibility of social and cultural adaptation

2. Work without face-to-face consultation worsened the result

3. Lack of a festive and joyful atmosphere

4. The deterioration of the development of cognitive and communication skills

5. Online education provides only basic skills

6. There is no enrichment and comprehensive development of the language personality

Inability to use a sufficiently wide range of types of work in the digital mode.

Thus, online education provides students with only basic knowledge, and the process of distance education does not provide comprehensive personal development. Due to the fact that teachers need to give students not only the amount of basic knowledge and a set of useful work skills, but also to develop a comprehensive personality who can independently develop and master new things, as well as a person who masters cultural and aesthetic values. 
"Scientists and teachers emphasize that students should not only be given the sum of basic knowledge and a set of useful work skills but also develop the ability to perceive and master new knowledge, types and forms of work, methods of organization and management, aesthetic and cultural values. Education should form a person's ability to be creative. The experience of the last decades of organizing the educational process in the world testifies to the approval of the concept of student-centered learning, the main principles of which are based on active learning, emphasis on deep study and understanding, increasing the rights and responsibilities of students, developing their independence, cooperation between the teacher and the student, mutual respect, and a reflexive approach to the educational process on the part of the teacher and student [24, p. 19]. Therefore, distance education should be an accompanying education in relation to traditional education. Distance education gains an effective role only in combination with traditional education and should in no way displace the latter.

\section{$5 \quad$ References}

[1] Akhmetova D.Z. (2020). "Ecological man" in the era of digitalization. Higher education in Russia. 2020. Vol. 29. No. 5. Pp. 117-126. https://doi.org/10.31992/0869-3617-2020-29-5$\underline{117-126}$

[2] Akhmetova D.Z., Artyukhina T.S., Bikbaeva M.R., Sakhnova I.A., Suchkov M.A., \& Zaitseva E.A. (2019). Digitalization and inclusive education: points of contact. Higher education in Russia. 2019. Vol. 29. No. 2. Pp. 141-150. https://doi.org/10.31992/0869-36172020-29-2-141-150

[3] Almaraz-Menendez, F., Maz-Machado, A., \& Lopez-Esteban, C. (2016). University Strategy and Digital Transformation in Higher Education Institutions: A Documentary Analysis. International Journal of Advanced Research. Vol. 4, no. 10, pp. 2284-2296. http://dx.doi. org/10.21474/IJAR01/2337

[4] Anisimova, T. I., Sabirova, F. M., \& Shatunova, O. V. (2020). Formation of design and research competencies in future teachers in the framework of STEAM education. International Journal of Emerging Technologies in Learning, 15(2), 204-217. https://doi.org/ $\underline{10.3991 / i j e t . v 15 i 02.11537}$

[5] Baidenko V.I., \& Selezneva N.A. (2018). Optics of the future view (article 3). Higher education in Russia. No. 12 (218). Pp. 120-132.

[6] Baltgailis, J. (2019). The issues of increasing the effectiveness of teaching comparative economics. Insights into Regional Development, 1(3), 190-199. https://doi.org/10.9770/ ird.2019.1.3(1)

[7] Beregovaya O.A., Lopatina S.S., \& Oturgasheva N.V. (2020). Tutor support as a tool for socio-cultural adaptation of foreign students in a Russian University. Higher education in Russia. Vol. 29. No. 1. Pp. 156-165. https://doi.org/10.31992/0869-3617-2020-29-1 $\underline{-156-165}$

[8] Bernardo-Hinesley, S. (2020). Linguistic Landscape in Educational Spaces. Journal of Culture and Values in Education, 3(2), 13-23. https://doi.org/10.46303/jcve.2020.10

[9] Brown, M. (2015). Six Trajectories for Digital Technology in Higher Education. Educause Review. Vol.50, no. 4, pp. 16-28. Available at: https://er.educause.edu/-/media/files/articledownloads/erm1541.pdf 
Paper - Organization of Project Work with the Help of Digital Technologies in Teaching Russian as a ...

[10] Chen, X., Xia, E., \& Jia, W. (2020). Utilisation status and user satisfaction of online education platforms. International Journal of Emerging Technologies in Learning, 15(19), 154170. https://doi.org/10.3991/ijet.v15i19.17415

[11] Collins, A., \& Halverson, R. (2009). Rethinking Education in the Age of Technology: The Digital Revolution and the Schools. New York: Teachers College Press. 192 p.

[12] Dexeus, C. (2019). The Deepening Effects of the Digital Revolution. In E. Fay-os-Solá, C. Cooper (Eds). The Future of Tourism: Innovation and Sustainability. https://doi.org/ 10.1007/978-3-319-89941-1

[13] Dudukalov, E. V., Rodionova, N. D., Sivakova, Y. E., Vyugova, E., Cheryomushkina, I. V., \& Popkova, E. G. (2016). Global innovational networks: Sense and role in development of global economy. Contemporary Economics, 10(4), 299-310. https://doi.org/10.5709/ce. $\underline{1897-9254.217}$

[14] Filimonova N.J., \& Seregina O.L. (2018) Formation of writing skills using essays when teaching a foreign language. Current issues of professional education. 2018. No. 3 (12). Pp. $18-22$.

[15] Gabidullina, F., Galiullin, R., Khakimova, I., \& Mansurov, I. (2020). Elitist education: Historical experience of the russian and tatar peoples. Journal of Social Studies Education Research, 11(1), 267-280.

[16] Goebel M., \& Zhang T. (2018). Trends in 2018: education and teaching in the European higher education area. European University Association, 2018. URL: https://eua.eu/downloads/publications/trends2018-learning-and-teaching-in-the-europeanhigher-educationarea.pdf

[17] Harvey Arce, N. P., \& Cuadros Valdivia, A. M. (2020). Adapting competitiveness and gamification to a digital platform for foreign language learning. International Journal of Emerging Technologies in Learning, 15(20), 194-209. https://doi.org/10.3991/ijet.v15i20.16135

[18] Kalimullina O. Tarman B., \& Stepanova I. (2021). Education in the Context of Digitalization and Culture: Evolution of the Teacher's Role, Pre-pandemic Overview. Journal of Ethnic and Cultural Studies, Vol. 8, No. 1, 226-238 https://doi.org/10.29333/ejecs/629

[19] Kamaldinova E. S., \& Sagitov R.V. (2014). Problem field of the modern educational system of Russia. Academic Council. 2014. No. 11.P. 57-62.

[20] Khamidulin, V.S. (2020). Development of a Model of Project-Based Learning. Higher Education in Russia. Vol. 29, no. 1, pp. 135-149. https://doi.org/10.31992/0869-3617-202029-1-135-149

[21] Kolmos A. (2009) Problem-Based and Project-Based Learning. Skovsmose O., Valero P., Christensen O.R. (Eds). University Science and Mathematics Education in Transition. Springer, Boston, MA, 2009. P. 261-280. https://doi.org/10.1007/978-0-387-09829-6_13

[22] Kuleshov A. (2020) Digitalization of education in Russia and the world. URL: https://akvobr.ru/cifrovizaciya_obrazovaniya_v_rossii_i_mire.html

[23] Kuzu, Ö.H. (2020). Digital Transformation in Higher Education: A Case Study on Strategic Plans. Higher Education in Russia, 29, 3, 9-23. https://doi.org/10.31992/0869-3617-201929-3-9-23

[24] Lazarenko V.A., Kalutsky P.V., Dremova N.B., \& Ovod A.I. (2020). Adaptation of higher medical education to the conditions of digitalization of healthcare. Higher education in Russia. 2020. Vol. 29. No. 1. Pp. 105-115. https://doi.org/10.31992/0869-3617-2020-29-1$\underline{105-115}$

[25] Nikolaevna, T. A., Nikolaevna, K. E., Kanafievna, K. R., \& Anatolyevna, G. S. (2019). Pitfalls and drawbacks in engineering education in Russia. Journal of Applied Engineering Science, 17(1), 43-51. https://doi.org/10.5937/jaes17-19097 
[26] Palyanitsina, A. N., \& Akhmedova, A. N. (2020). Implementing the case study method in a process of teaching oil engineers. Paper presented at the Journal of Physics: Conference Series, 1515(2). https://doi.org/10.1088/1742-6596/1515/2/022049

[27] Panova, E.P., \& Saenko, N.R. (2020). The role of digital technologies in the process of teaching students Russian as a foreign language. Service plus, 94-102. (In Russ.).

[28] Pedro, F. (2007). The New Millennium Learners: Challenging Our Views on Digital Technologies and Learning. Digital Kompetanse. Vol. 2, no. 4, pp. 244-264. https://doi.org/ 10.18261/issn1891-943x-2007-04-04

[29] Saenko, N. R., \& Panova, E. P. (2019). Opportunities of "the Club for foreign lovers of Russian language and culture" in the social and cultural adaptation of foreign students at the Moscow Polytechnic University. Service plus, 13(4), 82-89. (In Russ.)

[30] Samoilenko, V. (2017). Nursing education, continuing education and in practice training, research and digital technology application. International journal of nursing sciences, 4 , 343-344. https://doi.org/10.1016/j.ijnss.2017.10.011

[31] Sandkuhl, K. \& Lehmann, H. (2017). Digital Transformation in Higher Education - The Role of Enterprise Architectures and Portals. In A. Rossmann, A. Zimmermann (Eds). Digital Enterprise Computing. Bonn: Gesellschaft für Informatik, pp. 49-60. Available at: https://dl.gi.de/handle/20.500.12116/119;jsessionid=1A142A0814932BBEF0EE7D38 FA224CF9 [in Ger]

[32] Sazonova, Z. S., Arifullin, I. V., Feofanova, L.S., \& Shcherbakova, V. L. (2015) ProjectBased Learning in the Context of Student Life. Higher education in Russia,11, 114-118. [in Rus].

[33] Selvin N. (2014). Digital technologies and modern University: degrees of digitization. London and New York: Routledge, 2014. 156 p.

[34] Semikina J.G., \& Semikin D.V. (2019). Using project work to form the concept of "historical and cultural heritage" in the modern digital educational environment. Business. Education. Right. 2019. No. 3 (48). Pp. 399-403.

[35] Seres, L., Pavlicevic, V., \& Tumbas, P. (2018). Digital Transformation of Higher Education: Competing on Analytics. In: L.G. Chova, A.L. Martínez, I.C. Torres (Eds). 12th International Technology, Education and Development Conference (INTED2018) Conference Proceedings. Valencia, Spain: IATED Academy. 5-7 March, 2018. pp. 9491-9497. https://doi.org/10.21125/inted.2018.2348

[36] Starodubtsev, V.A., \& Ryashentsev, I.V. (2020). Distributed Online Course for Educator Training. Higher Education in Russia, 29, 4, 63-72. doi: 10.31992/0869-3617-2020-29-463-72 [in Rus]. https://doi.org/10.31992/0869-3617-2020-29-4-63-72

[37] Stacy, J., Fernández, Y., \& Reyes McGovern, E. (2020). El Instituto: Centering Language, Culture, and Power in Bilingual Teacher Professional Development. Journal of Culture and Values in Education, 3(2), 120-137. https://doi.org/10.46303/jcve.2020.16

[38] Thiele, A.K., Mai, J.A., \& Post, S. (2014). The Student Centered Classroom of the 21st Century: Integrating Web 2.0 Applications and Other Technology to Actively Engage Students. Journal of Physical Therapy Education. Vol. 28, no. 1, pp. 80-93. https://doi.org/ 10.1097/00001416-201410000-00014

[39] Touimi, Y. B., Hadioui, A., Faddouli, N. E., \& Bennani, S. (2020). Intelligent chatbot-LDA recommender system. International Journal of Emerging Technologies in Learning, 15(20), 4-20. https://doi.org/10.3991/ijet.v15i20.15657

[40] Tretyakova, T.V., Vlasova, E.Z., Barakhsanova. E.A., Prokopyev, M.S. \& Sorochinsky M.A. (2020). Digital Education as a New Vector of Development of Education in the Northern Regions. In Anikina Z. (eds) Integrating Engineering Education and Humanities for 
Paper - Organization of Project Work with the Help of Digital Technologies in Teaching Russian as a ...

Global Intercultural Perspectives. IEEHGIP 2020. Lecture Notes in Networks and Systems, 131. Springer, Cham. https://doi.org/10.1007/978-3-030-47415-7 93

[41] Usacheva O.V., \& Chernyakov M.K. (2020). Assessment of readiness of higher education institutions to transition to a digital educational environment. Higher education in Russia. 2020. Vol. 29. No. 5. Pp. 53-62. DOI: https://doi.org/10.31992/0869-3617-2020-29-5-53-62

[42] Yuzhakov V.N., \& Efremov A.A. (2018). Legal and organizational barriers to digitalization of education in the Russian Federation. Russian law: Education. Practice. The science. No. 6 (108). Pp. 18-24.

\section{Authors}

Elena P. Panova, Associate Professor, Department of Humanitarian Disciplines, Moscow Polytechnic University, Moscow, Russia.

Elena V. Tjumentseva, Associate Professor, Department of Russian Language, Volgograd state technical university, Volgograd, Russia. (email: study@vstu.ru)

Ilona A. Koroleva, Associate Professor, Volgograd State Social and Pedagogical University, Institute foreign people, Volgograd, Russian Federation (email: yakorol@vspu.ru).

EImira R. Ibragimova, Associate Professor in the Faculty of Philology and History (Department of Russian Language and Literature) at Yelabuga Institute (branch) of Kazan Federal University, Elabuga, Russia (email: ERIbragimova@kpfu.ru).

Vadim O. Samusenkov, Associate professor of Department of Prosthetic Dentistry, E.V. Borovsky Institute of Dentistry, I.M. Sechenov First Moscow State Medical University, Moscow, Russsia. Currently, author is responsible for practice, is the deputy head of the educational department of the Institute of Dentistry (email: samusenkov_v_o@staff.sechenov.ru).

Article submitted 2020-12-16. Resubmitted 2021-10-09. Final acceptance 2021-10-14. Final version published as submitted by the authors. 